\title{
Of Love and Light: A Case Report of End-of-Life Experiences
}

\author{
Natasha A. Tassell-Matamua, PhD \\ Kate Steadman, MA \\ Massey University
}

\begin{abstract}
Unusual occurrences at the end-of-life have been reported anecdotally over centuries yet have only recently attracted increased academic attention. Recent studies suggest commonality to end-of-life experiences (ELEs), which can be broadly categorized into six types. ELEs are relatively common, frequently occurring in terminally ill and palliative patients. They also reportedly have positive effects on the dying, facilitating more peaceful deaths. We present a case report of the death of a woman of Cook Island Māori and New Zealand Māori descent who died from cancer, as retrospectively reported by her husband. The case is interesting due to the number of ELEs occurring for the dying as well as significant others during the period leading up to, at the moment of, and after her death. The case is discussed in relation to previous findings on ELEs and resulting implications for enhancing understandings of the dying process and consciousness.
\end{abstract}

KEY WORDS: end-of-life experiences, deathbed visions, deathbed coincidences, terminal lucidity, Māori

Unusual phenomena leading up to and at the time of death have been reported anecdotally across many cultures and over many centuries (e.g., Aries, 1974; Faulkner, 1973; Sambhava, 1994). These phenomena contravene currently accepted norms of reality, which in modern Western societies are based on a reductionist, materialist philosophy emphasizing established scientific principles and laws, such as cause-

Natasha A. Tassell-Matamua, PhD, is a senior lecturer, and Kate Steadman, MA, is a doctoral student of clinical psychology, both in the School of Psychology, Massey University, Palmerston North, New Zealand. Correspondence regarding this article should be addressed to Dr. Tassell-Matamua at the School of Psychology, Massey University, Private Bag 11222, Palmerston North, New Zealand 4442; email: n.a.tassell -matamua@massey.ac.nz. 
and-effect, objectivity, materiality, positivism, and empirical verification (Fach, Atmanspacher, Landolt, Wyss, \& Rossler, 2013; Landolt et al., 2014). Given their deviation from these established norms, such phenomena have not traditionally been considered as fundamentally valuable (Fenwick, Lovelace, \& Brayne, 2010), and little empirical attention has been given to them. However, a growing number of researchers and practitioners have begun reporting the occurrence of these experiences and their potential importance for end-of-life care. The term nearing-death awareness was initially adopted by some researchers to describe such experiences (e.g., Callanan \& Kelley, 1992; Horacek, 1997). More recently, the term end-of-life experiences (ELEs) has been commonly used in the literature to describe these "physically impossible occurrences" that are "beyond the realm of human capabilities" (Barbato, Bluden, Reid, Irwin, \& Rodriguez, 1999, p. 30). Here, the term ELE will be used to refer to a range of such phenomena, which can occur in the weeks, days, or hours before the person dies or in the period surrounding the dying process (Callanan \& Kelley, 1992; Fenwick \& Brayne, 2011; Kerr, Donnelly, Wright, Kuszczak, Banas, Grant, \& Luczkiewicz, 2014).

Although ELEs occur in relation to the death of an individual, they are not limited to the dying person. They can also be experienced by those with a significant relationship to the dying person whether or not they are within physical proximity at the time of death (e.g., Alvarado, 2003; Fenwick, 2013; Moody, 2010). ELEs are commonly reported by terminally ill patients (e.g., Kerr et al., 2014), their significant others (e.g., Kellehear, Pogonet, Mindruta-Stratan, \& Gorelco, 2012; Moody, 2010; Muthumana, Kumari, Kellehear, Kumar, \& Moosa, 2010), and staff working in end-of-life care (e.g., Brayne, Lovelace, \& Fenwick, 2008; Callanan \& Kelley, 1992; McDonald, Murray, \& Atkin, 2014), probably because in the cases of terminally ill patients, death is a process extending over a period of time. However, reports of ELEs have also been provided by emergency staff in response to accidents in which a person has passed unexpectedly (Fenwick, 2013; Kelly, 2002). It is estimated that approximately $10 \%$ of all dying people maintain or retain consciousness prior to death, and of these, more than half will experience an ELE (Mazzarino-Willett, 2010). Given their incidence and phenomenology, Morse (1994) suggested ELEs should be considered as part of the spectrum of spiritual phenomena occurring during the dying process.

In this article we present the case of a young New Zealand Māori woman who died from breast cancer in 1985, as retrospectively re- 
ported by the woman's husband 29 years after her death. The case is of interest due to the variety of ELEs that reportedly occurred for the woman in addition to significant others in her life, leading up to, at the moment of, and shortly after her death. We first provide an overview of the various types of ELEs reported in the literature to date. The verbatim account of the events as presented by the woman's husband at interview is then provided. These events are discussed in relation to their similarity to the ELE types reported in the literature as well as reported aftereffects both for dying and non-dying individuals who have ELEs.

\section{Overview of ELEs}

Literature relating to ELEs is relatively minimal, and few empirical studies have investigated them. However, over the past several decades, and accelerated by the seminal work of Callanan and Kelley (1992), increasing attention has been given to documenting, describing, and retrospectively studying ELE accounts. From this literature, as well as anecdotal reports documented throughout the ages, it is apparent that a number of experiences fall under the umbrella term of ELEs. Although each experience is unique to the individual or persons experiencing the phenomena, Callanan and Kelley (1992) classified ELEs under the umbrella term of nearing death awareness, suggesting there are six different categories. Similarly, Fenwick (2013) suggested ELEs can be very generally categorized as one of six types. Here, we combine the categories suggested by these pioneering researchers and identify and describe ELEs as: deathbed communication, transition to another reality, something leaving the body, deathbed coincidences, perceiving a radiant light, and terminal lucidity.

Perhaps the most commonly reported ELE is deathbed communication-also known as deathbed visions (Fenwick, 2013). Deathbed communication occurs in real time and often involves the dying individual reporting that they see, hear, or can touch/have been touched by a loved one-usually someone who has passed before them and with whom they had a close emotional relationship (Alvarado, 2014; Lawrence \& Repede, 2013). For example, in their pioneering book, Callanan and Kelley (1992) described how the dying patient Laura 'saw' her daughter, who had died of breast cancer one year previous, waiting in a line that Laura herself felt she was required to join. Some dying people communicate instead, or in addition, with religious or spiritual figures (Fenwick et al., 2010). The dying may report the predeceased 
person or figure as speaking to them, motioning to them, or sitting next to them. They may appear to hold conversations with those they see. For example, Horacek (1997) related the account of the comedian Sam Kinison who, just prior to dying, appeared to be holding a conversation with someone whom others could not see. Although some experiencers initially express surprise at seeing someone they know is deceased, they often respond to these communications with happiness and excitement, and they report and/or appear to feel reassured by them (Callanan \& Kelley, 1992; Osis \& Haraldsson, 2012).

The dying person may begin having deathbed communications days before they actually pass. The communication may initially involve a deceased other standing in the doorway and then, over time, slowly moving closer and closer to the dying individual until the day of death (Fenwick, 2013; Horacek, 1997). Alternatively, the dying individual may converse with the deceased other weeks before their death, being informed that it is not yet their time and that they instead will make that journey on a specific day or at a specific hour (Callanan \& Kelley, 1992). Another example given by Horacek (1997) was the case of a husband who stated he would die in "two hours" (p. 155), and he subsequently did.

Recent researchers have found that $30-88 \%$ of participants reported experiencing at least one deathbed communication prior to death (Kellehear et al., 2012; Kerr et al., 2014; Muthumana et al., 2010). Those in close physical proximity to the dying person have themselves also reported communication, such as in the form of visions (Betty, 2006) or witnessing a loved one's transition into the light and being greeted by deceased others (e.g., Moody, 2010).

In a second type of experience during the period leading up to death, dying people may report, or appear to be, transitioning to another reality or dimension. They may describe going to "another plane of existence,", as in the case of Mark, related by Horacek (1997, p. 156). They may describe seeing a bright light, moving through a tunnel toward a light, or experiencing a beautiful garden or scene with colours and scents that appear more real than the current reality they live in. They may also report seeing deceased others or beings who they understand are there to assist them in the dying process (Callanan \& Kelley, 1992; Fenwick, 2013; Horacek, 1997; Osis \& Haraldsson, 2012). Episodes of transitioning may occur at the moment of death or over a period of days or weeks prior to death. As with deathbed communications, these experiences often serve to reassure the dying, with many claiming they know they are moving to a better reality or 
existence upon their death. Horacek (1997) described several cases in which transitioning prior to death enabled the dying to better prepare, or be less anxious, about the dying process. Carers or significant others of the deceased are often witness to these experiences, stating it is usually easy to distinguish when the dying are transitioning: "Sometimes people seem to oscillate between the two worlds for a bit, that can last for hours. They seem at some points to be in this world and at other points they're not" (Fenwick et al., 2010, p. 176). In a study of carer's experiences of ELEs, 48\% reported witnessing the apparent transition of patients to another reality (Fenwick et al., 2010).

A third type of ELE-seeing something leaving the body-is, perhaps unsurprisingly, always reported by those in close physical proximity to the dying person. Although varied, the common element to these ELEs is the appearance of something physical leaving the body at the apparent moment of death. Exactly what leaves is subject to speculation, but descriptions include a type of blue misty object, a bright light, or a hazy form (Alvarado, 2003; Fenwick \& Fenwick, 2008). Reports of a silver cord slowly ascending upwards have also been described (Kemp \& Bhungalia, 2002). The exiting entity almost always leaves from the head, chest, or mouth. It may appear to hover over the body for a short period of time before disappearing upwards (Fenwick, 2013). NDE accounts provide similar descriptions of consciousness 'hovering' over the body before journeying to an otherworldly place before returning to the physical body (see Tassell-Matamua, 2013 for an example). Moody (2010) described the case of a daughter during a 'shared-death experience' who, while the physical body of her mother lay on the floor below, felt her own consciousness was disembodied as she watched her now deceased mother drift into a light. Although no known studies have investigated the incidence of something leaving the body as witnessed by carers or significant others, Fenwick et al. (2010) found $35 \%$ of their sample of carers reported second-hand accounts of witnessing light surrounding another as they died. This light may be synonymous with the anecdotally reported exiting entity.

In a fourth type of ELE, deathbed coincidences, someone emotionally close to but physically separated from the dying person becomes acutely aware of the death. Deathbed coincidences take many forms. The significant other may have an overwhelming sense of emotion about the dying person, an intuitive feeling that the person has passed or is passing, or a visitation by or apparition of the dying person (Fenwick \& Brayne, 2011; Fenwick et al., 2007). Deathbed coincidences can occur when the significant other is awake or asleep. During sleep 
they take the form of a dream, although upon waking the person understands the dream is significant in indicating the passing of the deceased (Fenwick, 2013).

In their recent study, Fenwick and Brayne (2011) found 49\% of participants experienced a deathbed coincidence in which they felt the person had come to say goodbye and provide them with reassurance. Results also indicated $93 \%$ of such experiences were verified as coinciding with the timing of death. Deathbed coincidences may also take the form of some other synchronistic event that has special significance to the person, such as seeing particular animals (Brayne et al., 2008; Muthumana et al., 2010) or hearing a particular bird call that is identified and acknowledged as indicating or being associated with the impending or actual passing of the significant other (Fenwick et al., 2010). It should be noted that such coincidences are not restricted to expected deaths, such as in the case of people who are terminally ill whereby significant others are aware of their imminent passing. Visions of others have been recorded by those who had no expectation the individual would die or be dead and yet saw the person in a dream or 'real-time' vision or had some other synchronistic happening. Only later did the experiencer learn the person had, in fact, passed away at or close to the time of their vision, dream, or synchronistic happening and then retrospectively relate their experience to the passing of the other (see examples in Guggenheim \& Guggenheim, 1995).

Fifth, in the moments leading up to death, the dying may report seeing a radiant light. Though the dying person may be conscious and appearing to perceive the light in the physical environment, people in close physical proximity may or may not also perceive it. However, such persons also sometimes report seeing or perceiving a radiant light, usually just prior to or at the moment of death (for examples, see Alvarado, 2003). Often the radiant light is seen to surround the body of, or be in close physical proximity to, the dying person-or it may fill the room. The perception of light does not appear to be restricted to those with a close emotional relationship to the dying person, as hospice and palliative care workers have also described this experience while present at some patients' deaths (Callanan \& Kelley, 1992). In their study, Fenwick et al. (2010) found 35\% of their sample of carers reported second-hand accounts of witnessing light surrounding a dying person.

A sixth and particularly intriguing type of ELE is known as terminal lucidity. In these types of experiences, people who have suffered from severe cognitive deficits, such as psychiatric or neurological 
disorders including dementia, Alzheimer's disease, or chronic schizophrenia, or other chronic conditions such as brain tumors, meningitis, or strokes, appear to have a sudden and unexpected return of mental clarity just prior to death (Nahm \& Greyson, 2013). The dying individual who may not have communicated in a clear way for many years may suddenly hold a very lucid, rational, and comprehensible conversation; make comments indicating their awareness of events or circumstances others may not have considered them capable of perceiving (Brayne et al., 2008; Nahm, 2009); or sing songs and talk, even if they reportedly had never done so before due to conditions such as severe lifelong mental disability, as in the case of Anna Katharina Ehmer (Nahm \& Greyson, 2013). Instances of terminal lucidity may occur in the minutes, hours, or days preceding death (Nahm, Greyson, Kelly, \& Haraldsson, 2012). No known researcher has investigated the incidence of terminal lucidity, although Nahm and Greyson (2013) identified 83 cases in the literature from the past 250 years, and Fenwick (2013) suggested an incidence rate of approximately $6 \%$.

\section{Case Report}

The case report details the death of a 31-year old woman from breast cancer in 1985, as recollected by her husband. The woman was of Cook Islands Māori and New Zealand Māori descent. She was born in the Cook Islands and lived there until she was 10 years of age before immigrating to New Zealand, where she resided until her death. When she died, the woman was married and had three children aged 3, 6, and 8 years. At the time of her death, her husband was 30 years old. At the time of relating this account to us, her husband, the study participant, was 59 years old. He was of New Zealand Pākehā (European) descent and had previously been educated to university level, having completed a Bachelor of Arts in Philosophy and English. In the 29 years following her death, the participant had re-married and divorced and had not had any more children. At the time of interview, he was in a long-term relationship and was self-employed. When asked, the participant self-reported he had never suffered cognitive impairments and had no medical history of memory difficulties or mental illness.

He had previously related the account of his wife's death to one of us, co-author NTM, in May 2014. At this time, it was suggested to him that, given the number of ELEs that occurred in relation to the death, a formal documenting of the account may be of interest to a professional and academic audience. The participant stated if the case 
could benefit others in terms of raising awareness and understanding of events occurring at end-of-life, he would provide details in a formal capacity. Therefore, institutional ethical approval was sought and granted to conduct a formal interview with the participant to document the case.

The interview took place in December 2014 at the participant's home and lasted for approximately two hours. A semi-structured interview approach was used whereby the interviewers, NTM and KS, posed a series of questions (see Appendix) to which the participant was given time to freely respond to each in whichever way he chose; we sometimes posed follow-up questions to enable the participant to elaborate on or clarify what he had offered. The participant was offered compensation as acknowledgement of the time given for the interview.

We chose not to utilize a specific type of qualitative method to describe or analyze this case, as we did not wish to intentionally impose a perspective or inadvertently bias the presentation of information and our discussion of it. The case herein details the participant's recollection of the ELE-related events surrounding his wife's death. He provided details of the events leading up to her death, the apparent moment of her death, as well as shortly after. He also detailed the impact the ELEs have had on him. The names of persons and places mentioned in the narratives have been changed to protect privacy. Of note, NTM observed that the details the participant related in May 2014 were consistent with those he related in December 2014.

We begin the case by relating the narrative that the participants provided regarding the moment of death of his wife. In particular, when asked about whether there were any specific occurrences that happened when his wife died, the participant responded with the following verbatim account:

So we took KT home. So, I am not sure if we got the children home from school or let them have the day off school; I can't remember. It seemed appropriate when we got KT home, it was about 11 o'clock in the morning. It seemed appropriate to call KT's close friends and get the kids so we were all gathered around her. So we all gathered in the lounge, and KT was lying in the lounge. And then at about 1:30 pm you could see she was starting to pass away... Of course KT was lying on the couch, and she was the most peaceful of all of us. She was talking us through it [what was happening to her]. She said she was walking through a tunnel down into the light. She was very peaceful. She was talking along those lines of going to the light and how peaceful it was. And then she appeared to die. And then she woke up maybe half a minute later and said, "There is a heaven. I have been there, and it is beautiful." Then she died.... 
We wished to explore the participant's thoughts on the dying process of his wife and, in particular, what his thoughts were around her experience of apparently dying and then returning before dying once more. The participant explained:

KT and I had had many talks about what was happening before this. I said, "Let me know if there is a heaven." Of course I did not know how she was going to let me know... she kept a promise; that was one thing: She always kept a promise. And even when she died she kept her promise. And I find that quite exceptional, too.

We further queried the participant about his thoughts on this particular aspect of the ELEs and her dying process, and what his interpretation of it was:

I think with KT dying and then coming back, I would say that when she came back, her life thread or consciousness thread hadn't completely snapped at that time she was going down into that tunnel. I believe before she was completely isolated from ... before she was isolated from us, she came back before all contact was broken... When the consciousness is completely gone from this body, I believe that you can't make contact.

When questioned about how the moment of death was experienced by those present, the participant indicated that leading up to and at the moment of death, his wife appeared to be at great peace, while those gathered around her also appeared to be in a state of equanimity. He recounted:

That was the death experience on that day ... it was interesting because the children were all young...They were all calm and composed, even though KT was the most calm. She had a being-ness about hera calmness - so it was quite a soulful experience. Also I think on that day, I had never experienced death of a close person before. So you are going to the unknown... So it was quite a peaceful experience at the time. And then all the crying began afterwards. But at the time, it was peaceful.

The participant was asked whether any unusual phenomena occurred after the death of his wife. The term 'unusual phenomena' was not defined, as we did not want to impose an interpretation. The participant stated he did not recall experiencing anything personallysuch as dreams or visions of the deceased-in the 29 years following his wife's death. However, he did recall his thoughts and actions at the moment she died, and he reported the following to have occurred immediately after she drew her final breath: 
... then at that time, I thought, "I better open up a window here" for her soul to go out. So I opened up the window, and then a little while after that the curtains moved. It wasn't like there was something coming in; it was like there was something moving out. And then that was it. It was done.

In response to this description, we queried the participant as to whether he recalled others being aware of or commenting on the movement of the curtains:

Yes, you couldn't help but see it. The lounge [couch where the deceased was lying] was next to the window, so yeah, they would have experienced it.

Later in the interview, he also mentioned an unusual occurrence that had happened to his sister several years after the death of his wife. His sister had had a serious car accident and was hospitalized in the intensive care unit. She apparently went into cardiac arrest several times and, on one of those occasions, reported seeing the participant's deceased wife:

For my sister to pass over and come back and see KT over there, she $[\mathrm{KT}]$ must be somewhere.

Although the participant had previously related to NTM the occurrences at the moment of his wife's death, during the interview we were interested to determine whether the participant recalled any ELErelated phenomena occurring in the days, weeks, or months leading up to the death. The participant stated there were, and he detailed three incidences he felt were especially important in relation to his wife's death. Regarding the first incident, he described how his wife spent much time tidying the house and implied he felt she knew her death was imminent:

And with KT, I can look back now and see that she was an evolved soul, so she was taking it in her stride. So, all the panic was with me. So she went about the house and she cleaned the house top to toe. I said to her, "Take your time; there's no rush." She said, "No, it needs to be done."

Regarding the second incident, the participant described how his wife woke him in an excited state to relate to him a vision she had. Although he was not witness to it, the communication that occurred during the experience was later substantiated by a third-party who was unknown to either the participant or his wife at the time of her vision. He related her experience as follows: 
I am a light sleeper, so I can wake up at anything. But one night apparently I didn't wake up, and KT woke up and said, "Oh, I had the Lord Jesus come to me!" I said, "What happened?" She said, "Didn't you hear the rain?" I said, "No, I didn't." So she said, "Well, he made me get out of bed and get on my knees and pray for forgiveness, and as I was, it was raining, and the rain was washing me clean. I have been shown this man and this lady I have to ring up because they have a bible for me." So, she got hold of these people from the New Life Church and rang this minister up and said the Lord Jesus had come to her and that [the minister] had a bible for her. He said, "Yes," and he came around to our place and gave her this bible, which was the exact bible she had seen [in her vision].

The third incident relates to an experience the deceased's mother had prior to her death, in which she was made aware of the plight of her daughter, despite not having had contact with her for some time either prior to or since the diagnosis of illness:

Her mother had phoned one night and said that she was in [Name of place]. And, she said these owls-moreporks-came in and flew around the bay and told her to get ahold of KT because KT was sick. So we had not seen KT's mother for years. And, uh, she rang up and said, "Look, I was told you are not well," and KT said, "No, I have cancer." And, so her mother came up and spent time with us until KT died.

Given the impact extraordinary experiences can have on people, we were interested to determine whether the ELEs reported by the participant had resulted in any notable changes for him. In response, he discussed the impact his wife's death had on him before moving to a discussion related to the spiritual transformation he believed had occurred since the time of her death 29 years previous:

Well, one of the learnings I got from KT dying was I was working before I was... I was working between 60-80 hours a week. My belief was I had to make the money for my family... But after KT got sick and died, I realized it wasn't about making more money for my family, because the more money I made the more I would go and spend it on something else. Umm, she could have done with me being 'round and just having more of my time. That is probably one of the biggest things I learned. It wasn't about making money, because money was only a little bit important. What was more important was me being there with my family and being there with KT. So that was the learning that came out of that for me. And I have lived that ever since.

All my life since KT died, umm, has been steadily progressing toward the soul. And so I tend to live that life to a degree. I'm not a total soul; there is imperfections in there. But if I don't fix them in this lifetime, hopefully I will fix them next time. 
We were interested to learn a little more about the apparent spiritual transformation and, in particular, whether this transformation was a result of the death of a significant other or the result of the ELEs the participant had witnesseed and/or that others had recounted to him. The participant responded by discussing his lack of spirituality or religion during the time he was married to the deceased and then by proceeding to discuss his present beliefs:

We didn't live a religious life or spiritual life back then. It was more focused on the material/physical side of life. But yeah, when I look back, it was me that was always pushing to gain things materially. It wasn't so much KT ... it was ride motorbike, play rugby, work, go to the rugby club, drink. Not her, me.

I have been through my wild times. Now, I have polarized the mental times which has taught the soul... I study every morning... One of them is esoteric psychology. It's wonderful. It's about your growth as a soul and tells you about the personality, which is absolutely distinct from the soul. Then, another one I study is, umm... healing.

\section{Discussion}

The case report is interesting due to the number of ELEs occurring for the deceased and significant others to her, the duration over which these occurred, and their implications. To our knowledge, no current literature has identified as many ELEs occurring in relation to the death of a single person. A study in New Zealand revealed that NDEs of people who self-identified as Māori were significantly deeper than those of people who identified as Pākehā or European descent (TassellMatamua \& Murray, 2014); the extent to which more numerous ELEs might also be related to Māori cultural affiliation, as was, in this case study, the affiliation of the dying woman and her mother, remains a topic for future research. In this case, we identified five types experienced prior to, at the moment of, and after death. We categorize each ELE according to the time it occurred, discuss it in relation to previous research, and then discuss its aftereffects.

\section{Prior to Death}

A number of ELEs occurred for the deceased and significant others prior to her death. Perhaps the most significant was the communication of the deceased with the Lord Jesus. The participant stated he and his wife had not led a spiritual or religious life while she was 
alive, so it is interesting a religious figure was involved in the communication. This ELE is characteristic of deathbed communication, in which the dying person sees, hears, and speaks with a religious figure (e.g., Callanan \& Kelley, 1992; Fenwick et al., 2010). Although the husband did not detail exactly when this event occurred (i.e., how many weeks prior to death), he indicated it occurred after her diagnosis and when she knew she would be dying, and he did recall the deceased being very excited by the experience, noting she felt 'cleansed of her sins.' The 'cleansing experience' may have provided comfort or closure about her impending death and enabled enhanced psychological preparation for it. This speculation is supported by a growing body of evidence suggesting deathbed communications have beneficial effects on the dying (e.g., Callanan \& Kelley, 1992; Fenwick et al., 2010; Kerr et al., 2014; Lawrence \& Repede, 2013). Near-death experience (NDE) literature also speaks to the healing effects of previous NDEs, in which a religious or spiritual figure may have been encountered, on those who are dying (e.g., Horacek, 1997).

An even more intriguing aspect of this communication was the wife's claim to have been shown a man to call because he had a bible for her. It is not known whether the wife had previous contact with the New Life Church prior to her vision, although the participant did state that at the time of his wife's vision, she did not know the person she saw in her vision. She did subsequently search for and identify the man, who provided her a bible that matched what she had seen in her communication, suggesting a veridical aspect of the deathbed communication. Previous ELE reports have detailed information being provided to the dying person, most often indicating that they would die on a particular day or at a particular time (e.g., Callanan \& Kelley, 1992; Horacek, 1997). The dying person may communicate this information to significant others who later verify the accuracy of the 'prediction' about day or time of death (Fenwick, 2013; Horacek, 1997; Muthumana et al., 2010). It is difficult to ascertain the mechanism through which the receipt of detailed information could occur. However, such phenomena align with previous research on experiences outside the domain of end-of-life states that indicates communication of information through mechanisms other than the conventionally understood five senses appears to be possible (e.g., Radin \& Borges, 2009; Sheldrake, 2014). It also aligns with NDE reports of meeting deceased others, spiritual beings, and religious figures (e.g., Greyson, 2010a) and with cases of veridical (verified as accurate) NDE perceptions (Holden, 2009). Such reports suggest a transcendental element to near-death 
states. They also imply complex cognitive schemas are activated leading up to the moment of death.

A further ELE occurring prior to death was the experience of the deceased's mother. The participant described how the mother did not know of her daughter's illness but was made aware through communication with morepork owls. This experience is characteristic of deathbed coincidences whereby a significant other claims to have dreamt, had a 'real-time' vision, or seen or heard a particular animal that they recognize as symbolic and indicative of impending or actual death of another, even if that death is not anticipated or expected (e.g., Brayne et al., 2008; Guggenheim \& Guggenheim, 1995). The mother was of Māori descent. In Māori cultural mythology, the owl or moreporkalso known as ruru-have long been associated with the spirit world. Hearing, seeing, or having a ruru come into close proximity was considered a bad omen, usually signalling impending death of a close other (Kelly, 2012). It is not known how the mother communicated with the ruru, but her interpretation of their presence was presumably based on traditional Māori cultural beliefs about the symbolism surrounding ruru. This occurrence suggests ELEs of this nature may be endorsed and accepted as a norm of reality in some cultural groups, particularly Aotearoa New Zealand Māori. If so, it is also possible the wife endorsed such norms, which allowed for greater tolerance of and a stronger belief in ELE phenomena. This endorsement may, in turn, have allowed for a greater acceptance or possibility of occurrence of the ELEs. However, the husband did mention neither his wife nor he led a religious or spiritual life prior to her death, suggesting that although any culturally-specific beliefs surrounding ELEs may have been known to the wife, they may not have been valued prior to their occurrence.

\section{At the Moment of Death}

The moment of death heralded a number of features characteristic of ELEs for the dying woman. The participant explained how his wife 'talked him through' the dying process and, despite her illness, was lucid enough to describe her experience of seeing a bright light as well as her apparent travel through a tunnel. Such experiences characterize the perception of a radiant light and transitioning to another reality reported in other ELE studies (e.g., Alvarado, 2003; Callanan \& Kelley, 1992; Fenwick et al., 2010) as well as numerous accounts of NDEs.

The participant described the 'being-ness' of his wife and how he 
perceived she maintained a state of equanimity and peacefulness as she progressed through the dying process. It is not known whether the ELEs experienced prior to death (i.e., seeing the Lord Jesus) contributed to her mental state. However, Mazzarino-Willett (2010) suggested a growing body of evidence points to ELEs facilitating more peaceful deaths. Additionally, those present in the room at the moment of death also reportedly felt a sense of peace as she passed. The peaceful environment at the moment of death is commonly reported by those in the presence of people who have ELEs when they die (e.g., Lawrence \& Repede, 2012; Mazzarino-Willett, 2010). Therefore, the ELEs occurring prior to and at the moment of death may have facilitated a peaceful emotional state for the dying woman which, in turn, may have influenced the emotional state of those witnessing her death. This speculation suggests ELEs serve a therapeutic role for the dying which, in turn, has a concomitant effect on those present at the moment of death.

\section{After Death}

The apparent return to consciousness of the deceased to inform she had been to heaven is a particularly compelling ELE and is characteristic of the transitioning to another reality commonly reported by dying individuals (Callanan \& Kelley, 1992; Fenwick, 2013; Horacek, 1997; Osis \& Haraldsson, 2012). Although the reports known to us involved individuals transitioning between realities while still alive, this particular case is interesting as the participant described how his wife appeared to die before regaining consciousness momentarily to 'keep her promise' and let her husband know there was a heaven. Osis and Haraldsson (2012) reported a case of a man in India who regained consciousness after being pronounced dead, claiming he had gone to heaven but had been sent back by God because he had not completed his life. Two minutes later, the patient then passed away again. This additional case suggests, outside of NDEs, the act of regaining conscious abilities after apparent death and then dying shortly afterwards may be an occurrence more common than is currently reported in the literature.

Another important ELE occurring after death was the apparent gust of wind and movement of the curtain. Although the participant did not adhere to religious or spiritual beliefs at the time of his wife's death, he stated a need to open the window to allow his wife's soul to exit. He described seeing the curtains move as though something was 
exiting the window and that this movement would have been corroborated by others in the room. Nothing physical was manifested from the body, but this report is similar to descriptions of something leaving the body at the moment of or shortly after death, often cited in ELE research (e.g., Fenwick et al., 2010). It is also similar to accounts of other physical phenomena occurring at the moment of death, such as clocks stopping (Fenwick et al., 2009) and glass breaking (Osis \& Haraldsson, 2012). Witnessing something leaving the body at the moment of death or other apparently related physical phenomena may provide evidence the dying person has successfully "moved on" and may facilitate in survivors a sense of comfort about the passing. Combined, the transitioning and something leaving the body reported in this case suggest the possibility of a continuation of consciousness beyond physical death, in addition to some as yet unknown material entity leaving the body at the moment of death. Although challenging to conventional norms and objective, reductionist, scientific perspectives, these phenomena have implications for ongoing debates about the nature of consciousness and the afterlife (e.g., Greyson, 2010b; van Lommel, 2006, 2013; von Haesler \& Beauregard, 2013).

Although only scant details were provided, the participant described how during a period of cardiac arrest his critically injured sister had temporarily died and claimed to have met his deceased wife during what may have been an NDE. Reports of meeting and/or communicating with deceased others are prevalent in the NDE (e.g., Greyson, 2010a) and after-death communication (ADC) literature (e.g., Hannah, Botkin, Marrone, \& Streit-Horn, 2013; Streit-Horn, 2011). However, this particular occurrence is also similar to the deathbed communications reported by the dying in which they see a deceased other at the moment of, or in the minutes, hours, or days prior to, death (Alvarado, 2014; Callanan \& Kelley, 1992; Horacek, 1997; Lawrence \& Repede, 2013; Moody, 2010). This similarity suggests a commonality between ELEs, NDEs, and also possibly ADCs, and it points to a universality to the dying process. It may also contribute to ongoing arguments about the nature and possibility of post-mortem consciousness (e.g., Greyson, 2010a; van Lommel, 2006, 2013; von Haesler \& Beauregard, 2013).

\section{Aftereffects}

The participant indicated his wife's death had a profound impact on him. He discussed a variety of transformations occurring after her 
death and, in particular, pointed to his adopting a more spiritual approach to life. Research indicates many people experience positive psychological, emotional, and spiritual transformations after significant traumatic events, including death of a significant other, and these can occur in the absence of ELEs or other transcendental experiences such as NDEs (Bonanno, 2004). Therefore, it is difficult to ascertain what proportion of the participant's changes are attributable to the death itself and/or to the ELEs. Some credence deserves to be given to the participant's own assertion that his changes were the results of the ELEs rather than the death itself.

However, beyond participant testimony, research suggests ELEs have a profound and transformative effect on those who witness them (e.g., Mazzarino-Willett, 2010; McDonald et al., 2014; Muthumana et al., 2010). Although the reasons for this effect remain an area of future exploration, it is possible the ELEs provide some reassurance for witnesses. For example, witnessing transitions or something leaving the body at the moment of death could indicate the 'continuation' of the deceased in another dimension. Much has been written about the aftereffects of NDEs, both for those who experience them as well as for those who learn about them (e.g., Burton, 2011; Foster \& Holden, 2014; Holden, 2012). Of particular note is the more 'spiritual' approach to life embraced by near-death experiencers (NDErs) after their experience, with greater spiritual growth correlating with 'deeper' NDEs, whereby more of the typical elements of NDEs are experienced (Greyson \& Khana, 2014; Khana \& Greyson, 2014). Therefore, the transformative effects identified by the participant could possibly have resulted from the many ELEs-which, based on a quantitative assumption, may be synonymous with 'deeper' NDEs—occurring in relation to his wife's death. If so, this conjecture implies life changes of a profound nature may be facilitated by directly experiencing or being witness to altered states of consciousness. Greater understanding of such states could contribute to the development or enhancement of, for example, psychotherapeutic interventions aimed at increasing beneficial transformations.

\section{Limitations and Conclusion}

Before proceeding to conclusions, it is important to acknowledge the limits of this current case study. It is based on recollections of events that occurred nearly three decades before the interview. Though nothing in our experience with the participant leads us to doubt his verac- 
ity, unbenownst to him, his memory could very well have altered over time, thus causing him to inadvertently misrepresent events through omission, embellishment, or misremembering of aspects or timing of events. The correspondence of the participant's narrative to phenomena known through research to exist argues against error in his memory. However, the matter of accuracy of his memory cannot be settled definitively based on the data at hand. His case-of numerous ELEs associated with a single death and purported life changes resulting from them-represents a possibility that must be confirmed through further research. Hopefully, this study will provoke such research.

Indeed, academic research into the psychological state of those reporting extraordinary experiences leading up to and at the moment of death is scant. Research into the impact such experiences have on the dying, as well as those affected by their deaths, is similarly limited. What is known from the little research done to date is that exceptional experiences occurring at the end of life not only are frequent but also have profoundly beneficial effects on both the dying and survivors who witness them.

Death is inescapable. It comes to every person: to the ones we love and to the ones that love us in return. How we deal with death, that of our own and that of others, varies, but almost without exception, death will facilitate a rollercoaster of emotions. It seems ELEs could provide society with a means for learning more about the death process. ELEs could teach humanity about the psychological phenomenology of those who are dying. They could teach us about what we might expect when we die ourselves. They could teach us about how to respond constructively to death.

Health professionals working in palliative and end-of-life care typically report ELEs as a common aspect of their work. Although much has been written on the practicalities of providing end-of-life care, little education and training is provided to staff working with dying patients and their families who report ELEs (Brayne et al., 2008; Lawrence \& Repede, 2013). Therefore, more knowledge about and awareness of these extraordinary phenomena would provide such professionals with a more informed position from which to respond therapeutically to patients reporting ELEs, and it also could help significant others who witness or report them.

Finally, anecdotal reports as well as case reports such as this one suggest altered states of consciousness are prevalent at the end-of-life. Although differences exist between both NDEs and hallucinations (Sartori, 2004) and ELEs and hallucinations (Kircher, Callanan, \& 
the IANDS Board of Directors, 2011), the extent to which some aspects of ELE states might have a hallucinatory basis resulting from the physiological condition of dying is yet to be determined with certainty. In the absence of a definitive consensus, further exploration of ELEs should be done in relation to how they might contribute to advancing understandings of consciousness. Our hope in providing details of this case report is that awareness will be raised about the importance of ELEs, their phenomenology, and their implications-and that further research will ensue.

\section{References}

Alvarado, C. (2003). Neglected near-death phenomena. Journal of Near-Death Studies, 24, 131-151.

Alvarado, C. (2014). 'Visions of the dying' by James H. Hyslop (1907): With an introduction by Carlos S. Alvarado. History of Psychiatry, 25, 237-252.

Aries, P. (1974). Western attitudes towards death: From middle ages to the present. London, UK: Marion Boyars.

Barbato, M., Bluden, C., Reid, K., Irwin, H., \& Rodriguez, P. (1999). Parapsychological phenomena near the time of death. Journal of Palliative Care, 15, 30-37.

Betty, L.S. (2006). Are they hallucinations or are they real? The spirituality of deathbed and near-death visions. OMEGA: The Journal of Death and Dying, 53(1-2), 37-49.

Bonanno, G.A. (2004). Loss, trauma, and human resilience: Have we underestimated the human capacity to thrive after extremely aversive events? American Psychologist, 59, 20-28.

Brayne, S., Lovelace, H., \& Fenwick, P. (2008). End-of-life experiences and the dying process in a Gloucestershire nursing home as reported by nurses and care assistants. American Journal of Hospice and Palliative Care, 25, 195-206.

Burton, C. (2011). Counseling from a near-death perspective. Vital Signs, 22(1), 5-6, 14-15.

Callanan, M., \& Kelley, P. (1992). Final gifts: Understanding the special awareness, needs, and communications of the dying. New York, NY: Poseidon.

Fach, W., Atmanspacher, H., Landolt, K., Wyss, T., \& Rossler, W. (2013). A comparative study of exceptional experiences of clients seeking advice and of subjects in an ordinary population. Frontiers in Psychology, 4(Article 65), 1-9.

Faulkner, R.O. (1973). The ancient Egyptian coffin text. Warminster, UK: Avis and Phillips.

Fenwick, P. (2013). End-of-life experiences: A spiritual perspective. International Journal of Ethics, 9(3), 141-153.

Fenwick, P., \& Brayne, S. (2011). End-of-life experiences: Reaching out for compassion, communication, and connection-Meaning of deathbed visions and coincidences. American Journal of Hospice and Palliative Care, 28(7), 7-15.

Fenwick, P., \& Fenwick, E. (2008). The art of dying. London, UK: Continuum. 
Fenwick, P., Lovelace, H., \& Brayne, S. (2007). End of life experiences and implications for palliative care. International Journal of Environmental Studies, 64, 315-323.

Fenwick, P., Lovelace, H., \& Brayne, S. (2010). Comfort for the dying: Five year retrospective and one year prospective studies of end of life experiences. Archives of Gerontology, 51, 173-179.

Foster, R.D., \& Holden, J.M. (2014). Eternal connection: An exploratory study of the effects of learning about near-death experiences on adult grief. Journal of Loss and Trauma: International Perspectives on Stress and Coping, 19(1), 40-55.

Greyson, B. (2010a). Seeing dead people not known to have died: "Peak in Darien" experiences. Anthropology and Humanism, 35(2), 159-171.

Greyson, B. (2010b). Implications of near-death experiences for a postmaterialist psychology. Psychology of Religion and Spirituality, 2(1), 37-45.

Greyson, B., \& Khana, S. (2014). Spiritual transformation after near-death experiences. Spirituality in Clinical Practice, 1(1), 43-55.

Guggenheim, B., \& Guggenheim, J. (1995). Hello from heaven! New York. NY: Bantam Books.

Hannah, M.T., Botkin, A.L., Marrone, J.G., \& Streit-Horn, J. (2013). Induced after-death communication: An update. Journal of Near-Death Studies, 31(4), $213-220$.

Holden, J.M. (2009). Veridical perception in near-death experiences. In J.M. Holden, B. Greyson, \& D. James (Eds.), The handbook of near-death experiences: Thirty years of investigation (pp. 185-212). Santa Barbara, CA: Praeger/ ABC-CLIO.

Holden, J.M. (2012). After-math: Counting the aftereffects of potentially spiritually transformative experiences. Journal of Near-Death Studies, 31(2), 65-78.

Horacek, B.J. (1997). Amazing grace: The healing effects of near-death experiences on those dying and grieving. Journal of Near-Death Studies, 16(2), $149-161$.

Kellehear, A., Pogonet, V., Mindruta-Stratan, R., \& Gorelco, V. (2012). Deathbed visions from the Republic of Moldova: A content analysis of family observations. OMEGA: Journal of Death and Dying, 64(4), 303-317.

Kelly, K. (2012). 'Nga- manu-birds - Tohu - signs and predictions', Te Ara - the Encyclopedia of New Zealand. Retrieved from http://www.TeAra.govt.nz/en/ nga-manu-birds/page-3

Kelly, R.E. (2002). Post mortem contact by fatal injury victims with emergency service workers at the scenes of their death. Journal of Near-Death Studies, 21(1), 25-33.

Kemp, C., \& Bhungalia, S. (2002). Culture and the end of life: A review of major world religions. Journal of Hospice and Palliative Nursing, 4(4), 235-242.

Kerr, C. W., Donnelly, J.P., Wright, S.T., Kuszczak, S.M., Banas, A., Grant, P. C., \& Luczkiewicz, D.L. (2014). End-of-life dreams and visions: A longitudinal study of hospice patients' experiences. Journal of Palliative Medicine, 17(3), $1-8$.

Khana, S., \& Greyson, B. (2014). Near-death experiences and spiritual wellbeing. Journal of Religion and Health, 53(6), 1605-1615.

Kircher, P. M., Callanan, M., \& the IANDS Board of Directors. (2011). Near-death 
experiences and nearing death awareness in the terminally ill. Retrieved from http://iands.org/about-ndes/nde-and-the-terminally-ill.html

Landolt, K., Wittwer, A., Wyss, T., Unterassner, L., Fach, W., Krummenacher, P., . . . Rössler, W. (2014). Help-seeking in people with exceptional experiences: results from a general population sample. Frontiers in Public Health, 2(Article 51), 1-9. doi:10.3389/fpubh.2014.00051

Lawrence M., \& Repede, E. (2013). The incidence of deathbed communications and their impact on the dying process. American Journal of Hospice and Palliative Care, 30(7), 632-639.

Mazzarino-Willett, A. (2010). Deathbed phenomena: Its role in peaceful death and terminal restlessness. American Journal of Hospice and Palliative Care, 27, 127-133.

McDonald, C., Murray, C., \& Atkin, H. (2014). Palliative-care professionals' experiences of unusual spiritual phenomena at the end of life. Mental Health, Religion, and Culture, 17(5), 479-493.

Moody, R., with Perry, P. (2010). Glimpses of eternity: An investigation into shared death experiences. Auckland, New Zealand: Rider.

Morse, M. (1994). Parting visions. New York, NY: Harper Collins.

Muthumana, S.P., Kumari, M., Kellehear, A., Kumar, S., \& Moosa, F. (2010). Deathbed visions from India: A study of family observations in Northern Kerala. OMEGA: Journal of Death and Dying, 62(2), 97-109.

Nahm, M. (2009). Terminal lucidity in people with mental illness and other mental disability: An overview and implications for possible explanatory models. Journal of Near-Death Studies, 28(2), 87-106.

Nahm, M., \& Greyson, B. (2013). The death of Anna Katharina Ehmer: A case study in terminal lucidity. OMEGA: Journal of Death and Dying, 68(1), 77-87.

Nahm, M., Greyson, B., Kelly, E.W., \& Haraldsson, E. (2012). Terminal lucidity: A review and case collection. Archives of Gerontology and Geriatrics, 55, $138-142$.

Osis, K., \& Haraldsson, E. (2012). At the hour of death (rev. ed.). Guildford, UK: White Crow Books.

Radin, D., \& Borges, A. (2009). Intuition through time: What does the seer see? Explore: The Journal of Science and Healing, 5(4), 200-211.

Sambhava, P. (1994). The Tibetan book of the dead (Robert A.F. Thurman, Trans.). New York, NY: Bantam Books.

Sartori P. (2004). A prospective study of NDEs in an intensive therapy unit. Christian Parapsychologist, 16, 34-40.

Sheldrake, R. (2014). Telepathy in connection with telephone calls. Journal of International Society of Life Information Science, 32(1), 7-10.

Streit-Horn, J. (2011). A systematic review of research on after-death communication $(A D C)$ (Doctoral dissertation). Denton, TX: University of North Texas.

Tassell-Matamua, N. (2013). Phenomenology of near-death experiences: An analysis of a Māori case study. Journal of Near-Death Studies, 32(2), 107-117.

Tassell-Matamua, N., \& Murray, M. (2014). Near-death experiences: Quantitative findings from an Aotearoa New Zealand sample. Journal of Near-Death Studies, 33(1), 3-29.

van Lommel, P. (2006). Near-death experience, consciousness, and the brain. A new concept about the continuity of our consciousness based on recent scien- 
tific research on near-death experience in survivors of cardiac arrest. World Futures, 62, 134-151.

van Lommel, P. (2013). Non-local consciousness. A concept based on scientific research on near-death experiences during cardiac arrest. Journal of Consciousness Studies, 20, 7-48.

von Haesler, N.T., \& Beauregard, M. (2013). Near-death experiences in cardiac arrest: Implications for the concept of non-local mind. Revista de Psiquiatria Clínica, 40(5), 197-202.

\section{Appendix}

Interview Schedule

1. Can you please describe your relationship to the deceased that your ELE is in relation to?

2. Can you please explain the ELE/s?

a. When did the ELE/s occur?

b. Were there any specific features of the ELE/s that you consider to be especially important or unique?

c. Did other people indicate they witnessed the ELE/s, or aspects of the ELE/s?

3. Where there any other unusual phenomena that you [or others, including the deceased] experienced in the days or week prior to and/or after the death of the deceased?

a. When did these occur?

b. Were there any specific features of the phenomena that you consider to be especially important or unique?

c. Did other people indicate they witnessed the phenomena?

4. Can you please describe how you feel about the ELE/s

a. In relation to comfort at the death of the deceased

b. In relation to beliefs about the afterlife

c. In relation to beliefs about the continuation of consciousness

d. In relation to beliefs about the dying process

5. Is there any more you would like to add about your experience, its impact on you, and any other detail you think may be relevant? 